Review

\title{
NASA Data Used to Discover Eighth Planet Circling Distant Star
}

\author{
${ }^{1}$ Relly Victoria Petrescu, ${ }^{2}$ Raffaella Aversa, ${ }^{2}$ Antonio Apicella and ${ }^{1}$ Florian Ion Tiberiu Petrescu \\ ${ }^{I}$ ARoTMM-IFToMM, Bucharest Polytechnic University, Bucharest, (CE), Romania \\ ${ }^{2}$ Department of Architecture and Industrial Design, Advanced Material Lab, \\ Second University of Naples, 81031 Aversa (CE), Italy
}

Article history

Received: 09-01-2018

Revised: 13-01-2018

Accepted: 18-01-2018

Corresponding Author: Florian Ion Tiberiu Petrescu ARoTMM-IFToMM, Bucharest Polytechnic University, Bucharest, (CE), Romania

E-mail: scipub02@gmail.com
Abstract: Discovering the origins of life and colonizing extraterrestrial planets are two of the greatest ambitions that the international scientific community has today. Today, NASA is more prepared than ever to embark on an unprecedented race to conquer other worlds. The Kepler mission, named after Johannes Kepler, the German astronomer of the 16th-17th centuries, was scheduled to begin on March 7, 2009. In this mission, Space Agency released space from the Cape Canaveral Air Force Base, Florida, a Delta II rocket that will carry the Kepler space probe. It will try to identify Earth-like planets that orbitate stars similar to the Sun in a warm area of space, with liquid water and oxygen, that is, heavenly bodies that have all the conditions of life formation and maintenance. Kepler is looking for a new Earth. Kepler is a critical component of NASA's efforts to identify and study planets with Earth-like ecoconditions. The results of the Kepler space photometer will prove to be extremely important in understanding the frequency of Earth-sized planets in our galaxy. They will also plan future missions to directly detect and investigate such worlds near neighboring stars. Although more than 300 planets outside the solar system have already been identified by similar investigation technologies, Kepler's power resides in the high sensitivity of its instruments to smaller, cooler, more hospitable and more like us planes than all those identified so far. Kepler has a special telescope on board, which will study 100,000 astronomers from the Cygnus-Lyra region of the Milky Way for more than three and a half years. Scientists expect to discover hundreds of planets as large as the Earth or even larger, located at different distances from their stars. If the number of Earth-sized planets that have the potential to sustain life and be habitable of humans is great, Kepler could discover dozens of such celestial bodies; if they are rare, they may not discover any. "If we find that most stars have Earths, this implies that life development can be a common issue through our galaxy," says William Borucki, principal investigator at NASA's California Ames Research Center. "Discovery of only a few or a small number could indicate that we are alone in the Universe," the scientist added. Kepler's mission, according to the original English Kepler Mission, is a space mission, a cosmic station, a special cosmic ship and a space-based photometric telescope created and conducted by NASA to search for Terra planets in other solar systems. The Kepler cosmic station will observe and record the glow of more than 100,000 stars about 3-4 years in length to detect the periodic transition of a star's planets, a process of detecting the stars of a certain star called the transition method. The space mission is named in honor of German astronomer Johannes Kepler. A planet earth or a terrestrial planet in contrast to gaseous planets is a planet composed of rocks and metals that generally have three concentric shells (core or core, shell and bark or crust).

Keywords: NASA, Artificial Intelligence, Kepler, Exoplanet, Solar Systems 


\section{Introduction}

Our solar system now is tied for most number of planets around a single star, with the recent discovery of an eighth planet circling Kepler-90, a Sun-like star 2,545 light years from Earth. The planet was discovered in data from NASA's Kepler Space Telescope.

The newly-discovered Kepler-90i - a sizzling hot, rocky planet that orbits its star once every 14.4 days was found using machine learning from Google. Machine learning is an approach to artificial intelligence in which computers "learn." In this case, computers learned to identify planets by finding in Kepler data instances where the telescope recorded changes in starlight caused by planets beyond our solar system, known as exoplanets (Chou et al., 2017; Aversa et al., 2017a; 2017b; 2017c; 2017d; 2017e; 2016a; 2016b; 2016c; 2016d; 2016e; 2016f; 2016g; 2016h; 2016i; 2016j; 2016k; 20161; 2016m; 2016n; 2016o; Berto et al., 2016a; 2016b; 2016c; 2016d; Mirsayar et al., 2017; Petrescu and Petrescu, 2016a; 2016b; 2016c; 2013a; 2013b; 2013c; 2013d; 2012a; 2012b; 2012c; 2012d; 2011a; 2011b; Petrescu, 2016; 2012a; 2012b; 2009; Petrescu and Calautit, 2016a; 2016b; Petrescu et al., 2016a; 2016b; 2016c; Petrescu et al., 2017a; 2017b; 2017c; 2017d; 2017e; 2017f; 2017g; 2017h; 2017i; 2017j; 2017k; 2017l).

\section{Materials and Methods}

"Just as we expected, there are exciting discoveries lurking in our archived Kepler data, waiting for the right tool or technology to unearth them," said Paul Hertz, director of NASA's Astrophysics Division in Washington. "This finding shows that our data will be a treasure trove available to innovative researchers for years to come."

The discovery came about after researchers Christopher Shallue and Andrew Vanderburg trained a computer to learn how to identify exoplanets in the light readings recorded by Kepler - the minuscule change in brightness captured when a planet passed in front of, or transited, a star. Inspired by the way neurons connect in the human brain, this artificial "neural network" sifted through Kepler data and found weak transit signals from a previously-missed eighth planet orbiting Kepler-90, in the constellation Draco.

Machine learning has previously been used in searches of the Kepler database and this continuing research demonstrates that neural networks are a promising tool for finding some of the weakest signals of distant worlds.

Other planetary systems probably hold more promise for life than Kepler-90. About 30\% larger than Earth, Kepler-90i is so close to its star that its average surface temperature is believed to exceed $800^{\circ} \mathrm{C}$ Fahrenheit, on par with Mercury. Its outermost planet, Kepler-90h, orbits at a similar distance to its star as Earth does to the Sun.

"The Kepler-90 star system is like a mini version of our solar system. You have small planets inside and big planets outside, but everything is scrunched in much closer," said Vanderburg, a NASA Sagan Postdoctoral Fellow and astronomer at the University of Texas at Austin.

Shallue, a senior software engineer with Google's research team Google AI, came up with the idea to apply a neural network to Kepler data. He became interested in exoplanet discovery after learning that astronomy, like other branches of science, is rapidly being inundated with data as the technology for data collection from space advances.

"In my spare time, I started Googling for 'finding exoplanets with large data sets' and found out about the Kepler mission and the huge data set available," said Shallue. "Machine learning really shines in situations where there is so much data that humans can't search it for themselves."

Kepler's four-year dataset consists of 35,000 possible planetary signals. Automated tests and sometimes human eyes, are used to verify the most promising signals in the data. However, the weakest signals often are missed using these methods. Shallue and Vanderburg thought there could be more interesting exoplanet discoveries faintly lurking in the data.

First, they trained the neural network to identify transiting exoplanets using a set of 15,000 previously vetted signals from the Kepler exoplanet catalog. In the test set, the neural network correctly identified true planets and false positives $96 \%$ of the time. Then, with the neural network having "learned" to detect the pattern of a transiting exoplanet, the researchers directed their model to search for weaker signals in 670 star systems that already had multiple known planets. Their assumption was that multiple-planet systems would be the best places to look for more exoplanets.

"We got lots of false positives of planets, but also potentially more real planets," said Vanderburg. "It's like sifting through rocks to find jewels. If you have a finer sieve then you will catch more rocks but you might catch more jewels, as well."

Kepler-90i wasn't the only jewel this neural network sifted out. In the Kepler-80 system, they found the sixth planet. This one, the Earth-sized Kepler- $80 \mathrm{~g}$ and four of its neighboring planets form what is called a resonant chain - where planets are locked by their mutual gravity in a rhythmic orbital dance. The result is an extremely stable system, similar to the seven planets in the TRAPPIST-1 system.

Their research paper reporting these findings has been accepted for publication in The Astronomical Journal. Shallue and Vanderburg plan to apply their neural network to Kepler's full set of more than 150,000 stars. 
Kepler has produced an unprecedented data set for exoplanet hunting. After gazing at one patch of space for four years, the spacecraft now is operating on an extended mission and switches its field of view every 80 days.

"These results demonstrate the enduring value of Kepler's mission," said Jessie Dotson, Kepler's project scientist at NASA's Ames Research Center in California's Silicon Valley. "New ways of looking at the data - such as this early-stage research to apply machine learning algorithms - promise to continue to yield significant advances in our understanding of planetary systems around other stars. I'm sure there are more firsts in the data waiting for people to find them."

Ames manages the Kepler and K2 missions (Chou et al., 2017).

\section{Results}

Kepler's mission, according to the original English Kepler Mission, is a space mission, a cosmic station, a special cosmic ship and a space-based photometric telescope created and conducted by NASA to search for Terra planets in other solar systems (Kepler Mission). The Kepler cosmic station will observe and record the glow of more than 100,000 stars about 3-4 years in length to detect the periodic transition of a star's planets, a process of detecting the stars of a certain star called the transition method. The space mission is named in honor of German astronomer Johannes Kepler.

A planet earth or a terrestrial planet (Fig. 1), in contrast to gaseous planets, is a planet composed of rocks and metals that generally have three concentric shells (core or core, shell and bark or crust).

Discovering the origins of life and colonizing extraterrestrial planets are two of the greatest ambitions that the international scientific community has today. Today, NASA is more prepared than ever to embark on an unprecedented race to conquer other worlds. The Kepler mission, named after Johannes Kepler, the German astronomer of the 16th-17th centuries, was scheduled to begin on March 7, 2009. In this mission, Space Agency released space from the Cape Canaveral Air Force Base, Florida, a Delta II rocket that will carry the Kepler space probe. It will try to identify Earth-like planets that orbitate stars similar to the Sun in a warm area of space, with liquid water and oxygen, that is, heavenly bodies that have all the conditions of life formation and maintenance.

\section{Kepler is Looking for a New Earth}

Kepler is a critical component of NASA's efforts to identify and study planets with Earth-like ecoconditions. The results of the Kepler space photometer will prove to be extremely important in understanding the frequency of Earth-sized planets in our galaxy. They will also plan future missions to directly detect and investigate such worlds near neighboring stars. Although more than 300 planets outside the solar system have already been identified by similar investigation technologies, Kepler's power resides in the high sensitivity of its instruments to smaller, cooler, more hospitable and more like us planes than all those identified so far.

Kepler has a special telescope on board, which will study 100,000 astronomers from the Cygnus-Lyra region of the Milky Way for more than three and a half years. Scientists expect to discover hundreds of planets as large as the Earth or even larger, located at different distances from their stars. If the number of Earth-sized planets that have the potential to sustain life and be habitable of humans is great, Kepler could discover dozens of such celestial bodies; if they are rare, they may not discover any. "If we find that most stars have Earths, this implies that life development can be a common issue through our galaxy," says William Borucki, principal investigator at NASA's California Ames Research Center. "Discovery of only a few or a small number could indicate that we are alone in the Universe," the scientist added.

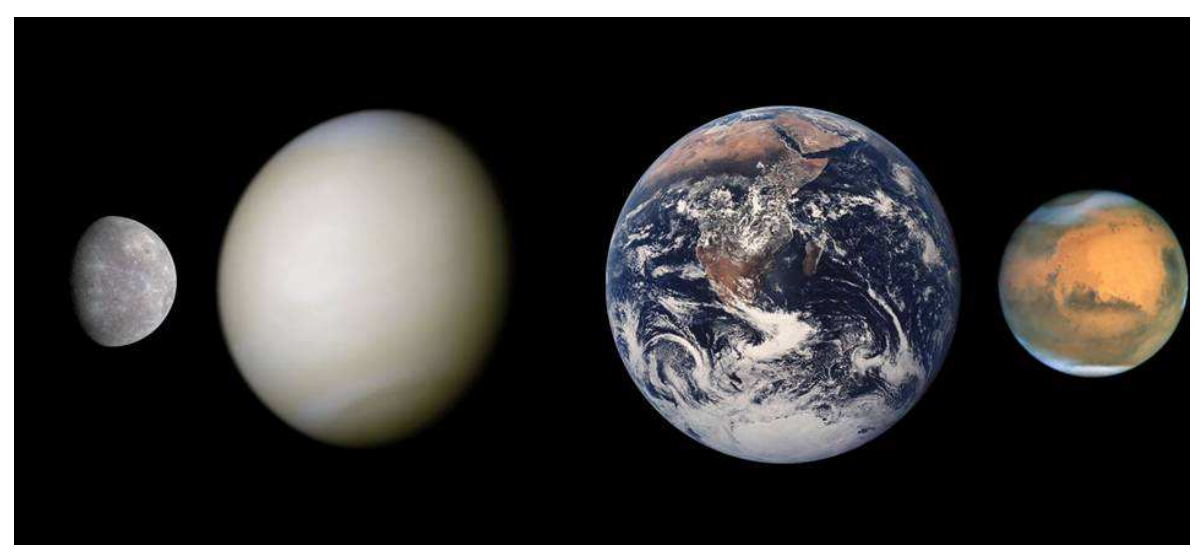

Fig. 1: Terrestrial or terrestrial planets in real-world colors: Mercury, Venus, Earth and Mars 
Astronomer Alan Boss, part of the Kepler's Strong Council, says the researchers should learn by 2013 if life could be spread through the universe. The discovery of intelligent alien civilizations is another problem. Besides all the speculation about the possibility of other civilizations in the Universe, the question arises whether the emergence of life on Earth is not a single case and the aliens exist, why did they not show up or why they have not contacted us so far? Physicist Enrico Fermi synthesized this contradiction in 1950, later becoming known as "Fermi's paradox": "Where is everyone?" The answer of the scientists is the infinite vastness of time and space.

The scientific objective of the Kepler mission is to explore the structure and diversity of planetary systems. This can be achieved by monitoring a considerable number of stars in order to achieve the following goals:

Determining the number of terrestrial planets within or near the habitable region of a wide variety of star types; Determining the range and shape of the orbits of these planets; Estimation of the number of planets existing in multislice systems; Determining the range of: Size of the orbits, brightness, size, mass and density of giant planets with short (or young) life; Identifying the additional components of each planetary system discovered; Determining the properties of those stars that host planetary systems.

In Fig. 2 and 3 one can see the last preparations before Kepler's departure.

However, Jan Hendrik Bredehoft of the University of the United Kingdom is one of the followers of the theory that mankind could populate other worlds. "I am one of those individuals who take a piece of meteorite, truncate it and find out what kind of organic chemistry is in its composition," says the researcher. Based on such studies, he came to the conclusion that living worlds can be divided into four major categories, with a high potential of being already the home of extraterrestrial life forms. The four groups of living planets imagined by Bredehoft are: Earth-like planets, Mars-like planets, astral bodies equivalent to Jupiter's natural satellite - Europe and wholly aquatic worlds.

Taking into account all these aspects, Bredehoft has calculated the possibility of each type of planet to host complex life on Earth. Earth-like worlds are undoubtedly the first class of hospitable planets and also promise increased "obedience," because we already know the extent to which these heavenly bodies are capable of hosting life. Earth-like worlds offer a good atmosphere, liquid water, moderate temperatures and stable climate.

The second class of planets is those that were once like the Earth, as is the case with Mars and Venus. "It's unclear why these planets, once fertile, have undergone radical transformation," says Bredehoft. "Mars has become too arid, with very little remaining water, at least in a liquid state and Venus has become extremely hot, among other things because of the greenhouse effect."

However, Bredehoft thinks that life is likely to exist on such worlds.

He reasoned that organisms might have developed when these planets were more hospitable and that life might have remained at some level of existence even in more hostile times. "Once life stabilizes, it's hard to quit altogether," says Bredehoft. "There have been devastating events in the history of the Earth that could annihilate any form of life, but ironically they have generally led to an increase in biodiversity rather than destroy it."

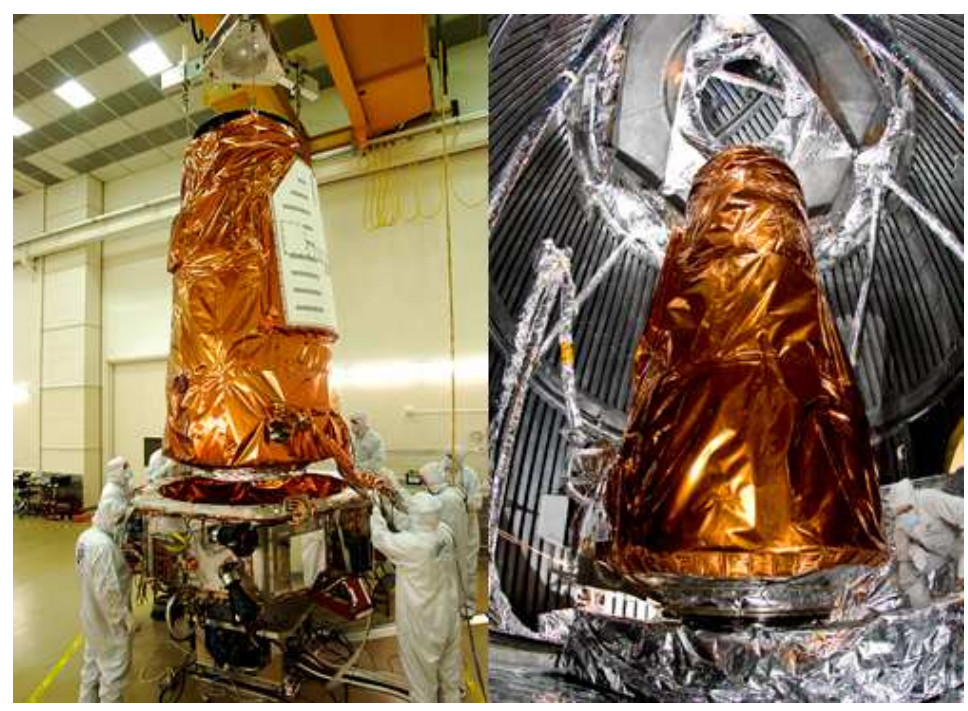

Fig. 2: Last preparations before departure 


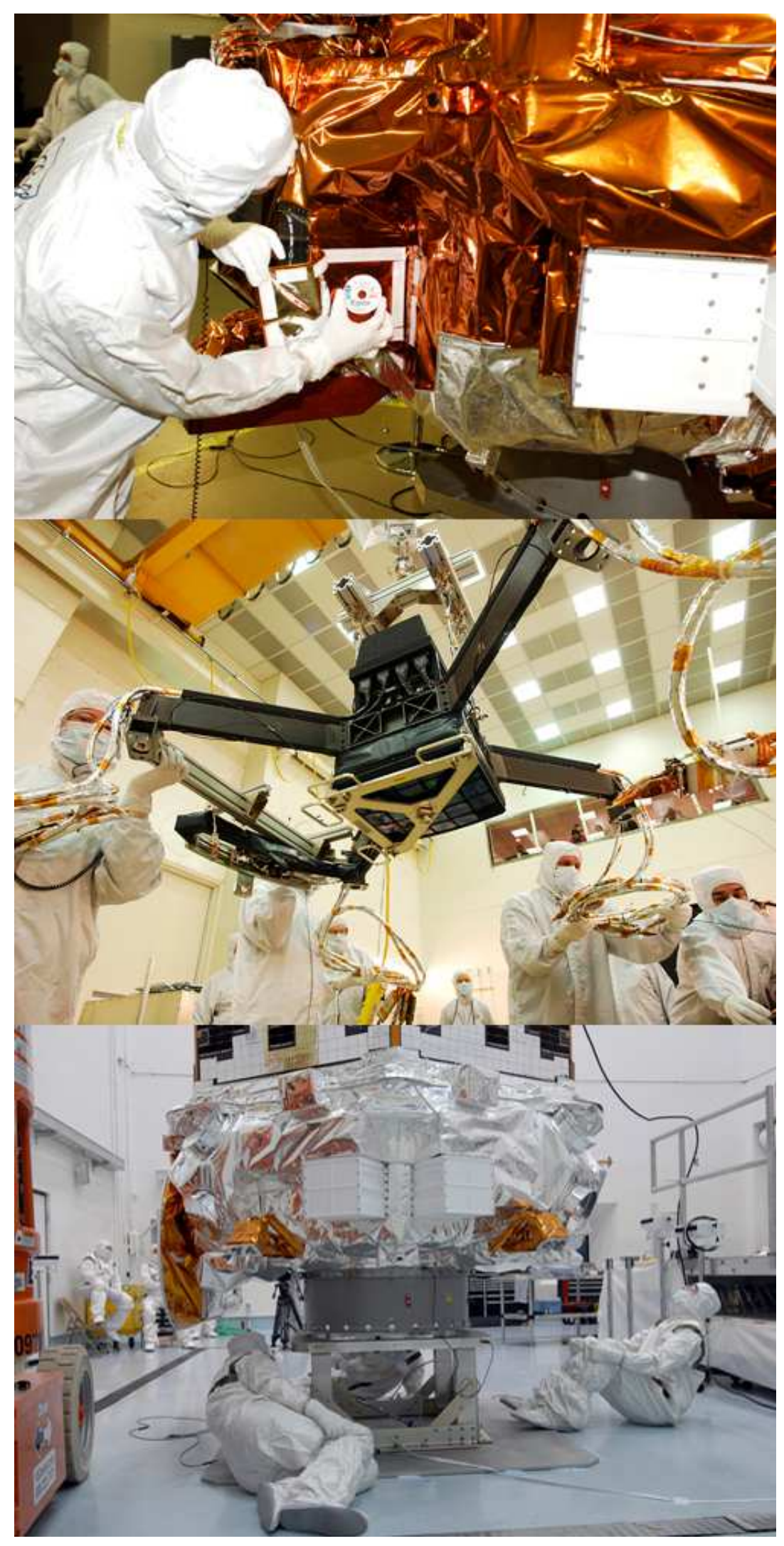

Fig. 3: Last preparations before departure 


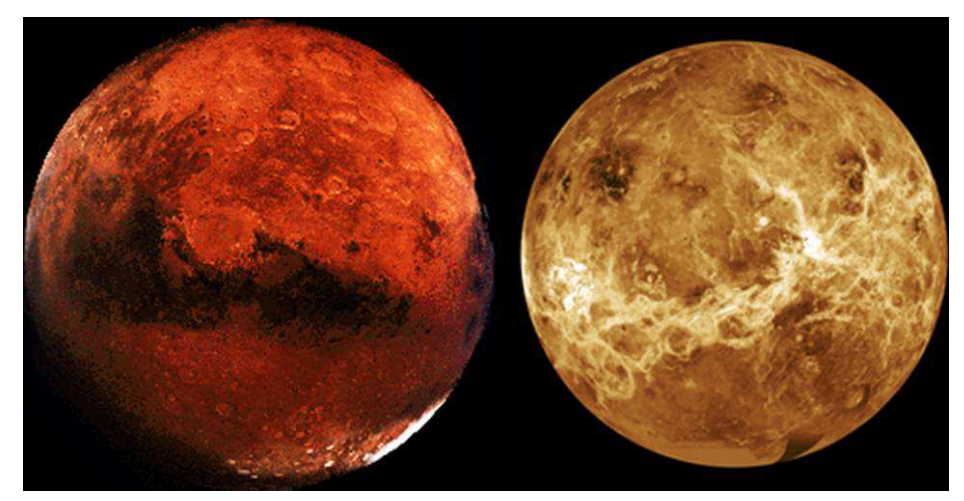

Fig. 4: Mars and Venus, two planets in the Solar System where there may have been (and yet still exist) life

Mars and Venus, two planets in the Solar System where there may have been (and yet still exist) life (Fig. 4).

The celestial bodies possessing liquid water, but not on the surface, but under a thick layer of ice, represent the third class of viable worlds. Jupiter's natural satellite, Europe, is a classic example of our own cosmic neighborhood. Could there be life in such places? Nowadays, it is hard to believe, because the living conditions of these worlds do not fit well into the conventional image of the habitable areas. Europe, for example, is beyond the solar thermal system where water can remain in the form of a liquid on the surface of the planet. However, there is potential for sustaining life. The traditional image of habitable areas generally refers to a local star as the main source of energy, as the Sun is now for us. But in frozen worlds, as is the case with Europe, other factors are being discussed, such as the gravitational pull of the planet around which the body is orbiting.

Whirlpools with ice water could be inhabited by simple organisms despite being out of conventional living space as long as one form of energy is provided in one way or another. The fourth type of living planets consists almost entirely of water. These hypothetical worlds would have the size of that of Mercury and that of the Earth and would have vast oceans. Unlike the Earth's oceans, the water on these planets would not come in contact with minerals or other rocks. "These bodies can be made entirely of water, with high-pressure ice in the core, or they can have liquid bodies separated by a mineral core through a thick layer of high-pressure ice," Bredehoft says.

Europe is the sixth month of Jupiter. The natural satellite of the largest planet in the Solar System was discovered in 1610 by Galileo Galilei (possibly by Simon Marius) and baptized by the Phoenician aristocracy of Europe, one of Zeus' wives, who later became Queen of Crete. Measuring only 3,100 kilometers in diameter, Europe is a little smaller than the moon that is orbiting the Earth and is the sixth largest moon in the Solar System (Fig. 5), (Safta A., KEPLER DAY).

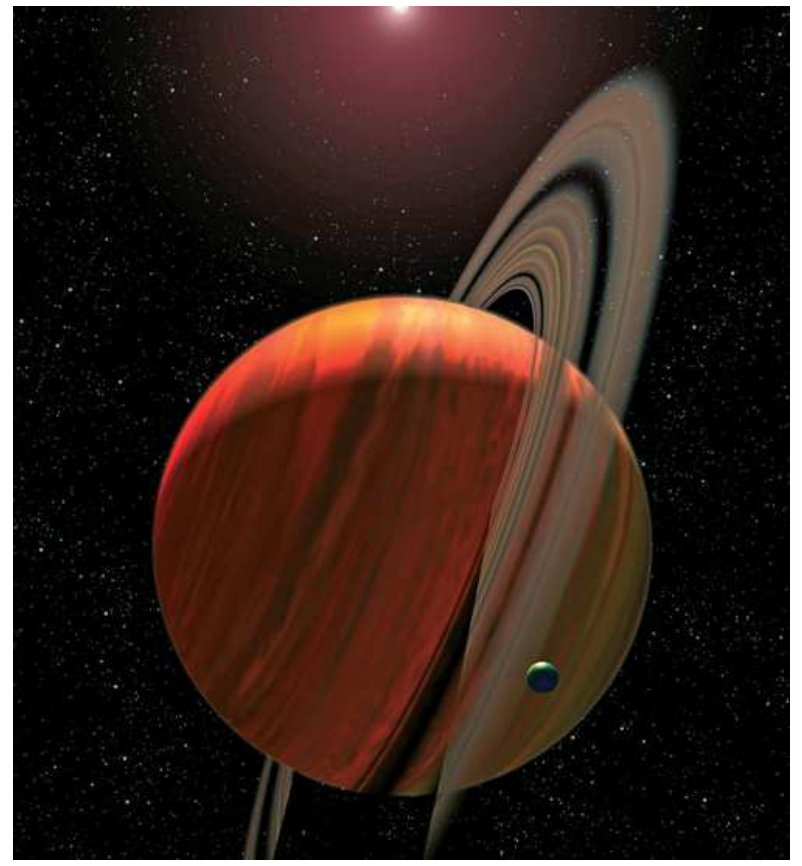

Fig. 5: Saturn with its rings and blue Europe, full of water, orbiting around Saturn

\section{Discussion}

More than 400 years have passed since the Italian philosopher Giordano Bruno was burnt for the boldness of imagining that the Universe is composed of a multitude of worlds similar to ours. His vision of the infinity of the world, then considered heretical, is about to be confirmed by astronomers.

The first such discovery was made by scientists at the Observatory in Geneva on October 6, 1995, when they identified a giant planet that gravitates around the 51 Pegasus star, about 40 light-years from Earth. Since then, over 300 extrasolar planets (or exoplanets that revolve around stars other than the Sun) have been identified and 20 stellar systems that concentrate a corps of planets. The orbital characteristics and physical 
properties of these newly discovered celestial bodies make it necessary to improve and update the theories about planet formation, especially to explain the existence of some for very short periods of time, to clarify their eccentric orbits and to justify certain physical properties, such as mass and nucleus. In addition, the stars around which gravity these planets are much richer in heavier elements than the Sun.

A first important finding: The diversity of planetary systems surpasses that of our solar system. Most of the extrasolar planets are giant (with a diameter of over $48,000 \mathrm{~km}$ ), at least as imposing as Jupiter, the largest planet of the solar system. But they are closer to their star than Mercury Sun and, in addition, they are moving in very elongated orbits, some even around stars floating freely through space. On the other hand, the predominance of very large planets could only be apparent as a result of the lack of precision and sensitivity of current detection tools and methods, which could not identify "small" planets of the Earth's dimensions. To discover new celestial bodies, astronomers use various methods, the most effective being velocimetry (measuring the velocity and direction of a fluid, for example, air). By velocimetry, astronomers calculate the variations in the radial velocity of the star around which gravitates the respective planets. But not all planets can be detected by this method. Given its current degree of accuracy, only planets with a mass of at least seven times the terrestrial mass can be identified. If Velocimetry is applied to our solar system, only Jupiter could be identified. NASA's Kepler mission will solve this problem, scientists hope.

Despite the difficulties encountered in detecting smaller astronomers, astronomers have identified the first land-based planet that does not revolve around the Sun. The discovery, baptized "poetic" OGLE 2005BLG-390Lb, is the extrasolar with the smallest of the masses known so far (only 5.5 times the mass of the Earth) and is located against its star at a distance of two and a half higher than the Sun's Earth. Composed of rocks and almost devoid of atmosphere, it contrasts with the rest of the giant planets, which are gaseous, just like Jupiter. The novelty among extras is different from its suits and other features. The star around which gravitates, at 22,000 light-years from the Earth, is the type of the smallest and weakest of the stars, it is red and its mass represents about one-fifth of the sun's mass. With ten billion years of existence, she is twice as old as our solar system. But as the OGLE 2005-BLG-390Lb is far away from its star, which emits a hundred times less light than our Sun, the amount of energy it receives is very low. Therefore, the surface temperature should not exceed $220^{\circ} \mathrm{C}$ Celsius. The planet's soil is composed of rocks and ice, so if we compare it to one of the planets of our solar system, OGLE would resemble Pluto rather than Earth-like astrologers like Earth or Venus.
The distance between OGLE and the star also raises the problem of the presence of liquid water. The surface temperature is extremely low, the existence of oceans to cover the planet is impossible. But liquid water could be found between a surface frozen crust and a layer of compressed ice that surrounds a stony region (in analogy with Europe, a Jupiter satellite). Maintaining liquid water would depend on the heat generated by the disintegration of the radioactive elements inside the rocks. This internal heating phenomenon takes place in a time frame comparable to the age of the planet. In addition, heat production diminishes with the passage of time and OGLE 2005-BLG-390Lb is no longer a young one ... It is therefore unlikely that there is a life on such a planet.

Given the variety of new planetary systems discovered over the last ten years, scientists have been forced to revise their planet-forming theories. Paradoxically, the first to advance a hypothesis about the appearance of the celestial bodies was a philosopher, Immanuel Kant, passionate about the problems of celestial mechanics. In 1775, he imagined our solar system emerged from a cloud of dispersed particles that, due to the gravitational interaction, collided with each other and formed, under the effect of "chemical forces," planets.

Pierre Simon de Laplace took up the idea that the solar system emerged from a nebula in motion and gave it a scientific basis, publishing in 1796 in his Exposition du Système du Monde, the "nebulous hypothesis." According to it, the planets are born from a cloud of gas and dust in motion that collapses when it cools and thus accelerates. Underlying both gravitational force and centrifugal force, the material rings detach from the nebula and form the planets. This is the so-called KantLaplace theory. Since then, the assumptions about the appearance of the planets have evolved and some ideas of Kant and Laplace have been confirmed. However, until recently, the only "sample" astronomers could test these theories was the Solar System, with its nine planets, with satellites and miriades of small bodies. The discovery of OGLE 2005-BLG-390Lb overwhelmed the whole field of research in a single shot and at the same time responded to the expectations of those looking for the sky in search of other worlds.

Most of the planet systems discovered to date are radically different from our solar system. For this reason, the imagination of astronomers has been hard to try. Nearly all extrasolar planets resemble giant planets like Jupiter and Saturn, but a fifth of them gravitates very close to their star (at hundreds of times smaller than Earth and Sun), with periods of revolution several days. Faced with this anomaly, the theories about the occurrence of the planets were, if not completely under questioned, at least reanalyzed.

Laplace was right in several respects: The stars, the Sun in particular, appear as a result of the gravitational 
contraction of gas clouds and circular motion dust. Following rotation, the generated contraction results in the formation of a flattened disc. All observations over the past 20 years indicate that some of the material of that disc deviates spirally to the center, to be ultimately captured by the star. There is enough certainty that these disks represent the place of planet formation, which has attracted the name of protoplanetal discs. Plants of tellurium or giant, all formed from such disks of gas and dust.

Today it is known that tellurian planets (composed mainly of rocks or metals, with a relatively high density, a slow rotation movement and a solid surface, which do not have rings and have few satellites, eg Mercury, Venus, Terra or Mars) they are born by the successive accumulation of solid materials consisting of elements that have condensed around the protoplanetary discs. This theory, advanced in the nineteenth century, was developed only in the 1960s. XX, by researchers at the University of Moscow. They proposed a detailed calculation of the stages of the formation of the planets. In short, protoplanetary discs are primarily composed of hydrogen and helium, plus $1 \%$ of dust. The size of the dust seed is in the order of a millionth of a millimeter. But, despite this, they play a fundamental role in the formation of planets, being their basic stuff. In a first step, the dust is settled. Like the gas, he is subject to the star's gravitational pull and collides with other molecules. The force of gravity tends to group the particles into the equatorial plane of the disk. The collision between the gas molecules causes a pressure that tends to disperse them, so the gas stays suspended on both sides of the equatorial plane. Instead, the collision of dust wires, with each other, or with gas molecules, is not enough to prevent them from sticking to the plane of the disk where they are gathering. In this way, in tens of billions of years or more, a thin layer of 1 centimeter dust is formed on the equatorial plane of the disk. However, the transformation of dusts into kilometer-sized planets remains a subject of controversy.

As for the appearance of large planets, there are two theories. The first, launched in the $1950 \mathrm{~s}$ by Gerard Kuiper, is related to that imagined by Laplace, according to which giant planets are the result of the weakening of the gravitational force and the fragmentation of a massive protostelar disk. Most numerical simulations, however, show that such a process would lead to the formation of Jupiter-sized planets too little. The second theory was proposed in 1973 by researchers at the Center for Astrophysics at Harvard University. According to her, a nucleus is first formed in the same way as in the tellurian planets, after which it becomes massive enough to capture large amounts of gas that will form the atmosphere of the planet. But theory has an inconvenience: The one of time. The core must become large enough to be surrounded by a gas coat and it is forced to grow before this coating is scattered.

To be able to form, giant planets need a much more massive nucleus than the tellurian planets. Therefore, it is believed that they occur below the limit of which is sufficiently cold for water, hydrogen or carbon to remain in solid form. As I said, once formed, the nucleus of the future giant planet must "equip itself" with the atmosphere. It is supposed that the gas disappears around that planet at the end of several tens of millions of years. If smaller tellurian planets, made up of heavy elements only, can complete their growth in a gas-free environment, the giant planets, in turn, must be formed as long as the disc is still rich in gas. The complete formation of a giant giant planet in a shorter time than prototype disk life remains a challenge for scientists. The theory of large-scale planet formation is applied only to some of them. Uranus and Neptune, for example, could not capture a massive atmosphere, while Jupiter and Saturn are mainly composed of gas because their core has reached critical mass.

Another process, discovered more than 20 years ago, talked about the migration of planets. Due to lack of data and confirmation possibilities, the theory was abandoned. After discovering the first extrasolar planet, OGLE 2005-BLG-390Lb, the idea was resumed, becoming a central part of the hypothesis about the formation of planetary systems. Migration is based on the gravitational interaction of the protoplanet with the surrounding gas, as it is about the type of tide created between the Moon and the Earth. It is known that the Earth rotates around its axis faster than the Moon around the Earth, respectively a day versus 27 days. The result: The moon's attraction to the Earth slows down, imperceptibly, its rotation. Instead, the moon's kinetic momentum increases, which, according to Kepler's laws, pushes it into a higher orbit. Thus, the Moon is moving away from our planet.

A planet embryo hidden in a protoplanetary disk exerts similar tidal effects on gas in its gravitational area. The planet moves more slowly than the gas, so that by the same mechanism a fraction of the kinetic moment of the system is transferred from gas to the protoplanet, which makes it fall into a lower orbit, the planet being pushed on a orbit more distant. Conversely, the gravitational interaction with the gas outside the protoplanet's orbit pushes the planet into a lower orbit. These gravitational interactions have different effects, depending on the gas/planet mass ratio. For example, if the mass of the planet is negligible compared to the surrounding gas, the orbit of the gas will not change in an observable way, while the protoplanet's orbit will do it.

Scientists still have many unanswered questions. But once on this road, there is no way back. It is estimated that by 2050 , the researchers will have interferometric spatial 
telescopes capable of identifying Earth-sized planets and telling them precisely if they can accommodate life forms. Currently, the only method for detecting extrasolar planes uses the microlentile phenomenon (or gravitational lenses), which causes a star to appear temporarily brighter than it actually is. Obviously, astronomers do not directly observe the heavenly bodies, but only the effects of their mass. The future sounds good.

Terrestrial extrasolar planets awaken a special interest, because it resembles the Earth and thus it can host life forms. However, the technical limits still do not allow the detection of small-sized celestial bodies, the smallest tellurian planets discovered having an average of about twelve times the mass of the Earth. The "tiniest" ever remains OGLE 2005-BLG-390Lb, with a mass 5.5 times the Earth's mass. It is located in the constellation of the Sagittarius, close to the middle of the Milky Way, being the farthest planet identified so far. Its orbit is three times farther from the star around which gravitates than Earth's orbit to the Sun, OGLE 2005-BLG-390Lb performing a revolutionary move in about ten years. This planet, with a temperature close to that of Neptune or Pluto, is too cold to accommodate life forms.

\section{Kepler's Laws}

In astronomy, Kepler's laws describe the movements of the planets around the Sun (or around the star of the planetary system) and, in general, the behavior of any two-body system between which a force inversely proportional to the square of the distance acts. The three laws were enacted in the early 17 th century by German astronomer Johannes Kepler, who used the observations made by Danish astronomer Tycho Brahe on the planet's orbit. These laws are valid only in the Newtonian mechanics system. The first two were published in 1609 in Astronomy nova, the third in 1619 in Harmonices mundi. These theses have led to the definitive rupture of the centuries-long belief that the planets would move around the Sun on circular trajectories. Kepler's laws formed the basis for Isaac Newton's formulation of gravity laws and are of particular importance for understanding the movement of the celestial bodies, for example, of the Earth and other planets, around the Sun, or of the Moon and the artificial satellites around Earth.

Computer-generated research has shown that $50 \%$ of the exoplanetary systems could contain a planet with the characteristics of the Earth and a lifetime of at least one billion years - the minimum time required for life to appear on such a planet. Around each star there is, in theory, an area where physical conditions (especially temperature) are compatible with the existence of life, at least as we know it. The European Space Agency prepares several missions whose ambitious goal is to discover new tellurian planets and then determine the probability that they will be habitable or, moreover, inhabited. For this, infrared spectroscopy will attempt to define the composition of the exoplanet's atmosphere in order to detect $\mathrm{CO}_{2}$ traces. The other elements discovered will be able to give information about the level of the planet's biology. Thus, the eventual presence of $\mathrm{H}_{2} \mathrm{O}$ and $\mathrm{O}_{3}$ would imply terrestrial conditions and the presence of $\mathrm{CH}_{4}$ and $\mathrm{O}_{2}$ would indicate a chemical balance that could suggest the presence of biological life forms (Zaporojanu, KEPLER DAY).

\section{Conclusion}

Discovering the origins of life and colonizing extraterrestrial planets are two of the greatest ambitions that the international scientific community has today. Today, NASA is more prepared than ever to embark on an unprecedented race to conquer other worlds. The Kepler mission, named after Johannes Kepler, the German astronomer of the 16th-17th centuries, was scheduled to begin on March 7, 2009. In this mission, Space Agency released space from the Cape Canaveral Air Force Base, Florida, a Delta II rocket that will carry the Kepler space probe. It will try to identify Earth-like planets that orbitate stars similar to the Sun in a warm area of space, with liquid water and oxygen, that is, heavenly bodies that have all the conditions of life formation and maintenance.

Kepler is a critical component of NASA's efforts to identify and study planets with Earth-like ecoconditions. The results of the Kepler space photometer will prove to be extremely important in understanding the frequency of Earth-sized planets in our galaxy. They will also plan future missions to directly detect and investigate such worlds near neighboring stars. Although more than 300 planets outside the solar system have already been identified by similar investigation technologies, Kepler's power resides in the high sensitivity of its instruments to smaller, cooler, more hospitable and more like us planes than all those identified so far.

Kepler has a special telescope on board, which will study 100,000 astronomers from the Cygnus-Lyra region of the Milky Way for more than three and a half years. Scientists expect to discover hundreds of planets as large as the Earth or even larger, located at different distances from their stars. If the number of Earth-sized planets that have the potential to sustain life and be habitable of humans is great, Kepler could discover dozens of such celestial bodies; if they are rare, they may not discover any. "If we find that most stars have Earths, this implies that life development can be a common issue through our galaxy," says William Borucki, principal investigator at NASA's California Ames Research Center. "Discovery of only a few or a small number could indicate that we are alone in the Universe," the scientist added. 


\section{Acknowledgement}

We acknowledge and thank $\mathrm{Mr}$ Taher M. AbuLebdeh, Associate Prof at North Carolina A and T State Univesity, United States and Mr Muftah H. El-Naas PhD MCIC FICCE QAFCO Chair Professor in Chemical Process Engineering Gas Processing Center College of Engineering Qatar University and Ms Shweta Agarwala, Senior Research Scientist at Singapore Center for 3D Printing Nanyang Technological University Singapore for their suggestions and comments.

\section{Funding Information}

Research contract: Contract number 36-5-4D/1986 from 24IV1985, beneficiary CNST RO (Romanian National Center for Science and Technology) Improving dynamic mechanisms internal combustion engines. All these matters are copyrighted. Copyrights: 548-cgiywDssin, from: 22-042010, 08:48:48.

\section{Author's Contributions}

All the authors contributed equally to prepare, develop and carry out this manuscript.

\section{Ethics}

This article is original and contains unpublished material. The corresponding author confirms that all of the other authors have read and approved the manuscript and no ethical issues involved.

\section{References}

Aversa, R., F.I.T. Petrescu, R.V. Petrescu and A. Apicella, 2016a. Biomimetic FEA bone modeling for customized hybrid biological prostheses development. Am. J. Applied Sci., 13: 1060-1067. DOI: 10.3844/ajassp.2016.1060.1067

Aversa, R., D. Parcesepe, R.V. Petrescu, G. Chen and F.I.T. Petrescu et al., 2016b. Glassy amorphous metal injection molded induced morphological defects. Am. J. Applied Sci., 13: 1476-1482.

DOI: 10.3844/ajassp.2016.1476.1482

Aversa, R., R.V. Petrescu, F.I.T. Petrescu and A. Apicella, 2016c. Smart-factory: Optimization and process control of composite centrifuged pipes. Am. J. Applied Sci., 13: 1330-1341. DOI: $10.3844 /$ ajassp.2016.1330.1341

Aversa, R., F. Tamburrino, R.V. Petrescu, F.I.T. Petrescu and M. Artur et al., 2016d. Biomechanically inspired shape memory effect machines driven by muscle like acting NiTi alloys. Am. J. Applied Sci., 13: 1264-1271. DOI: 10.3844/ajassp.2016.1264.1271
Aversa, R., E.M. Buzea, R.V. Petrescu, A. Apicella and M. Neacsa et al., 2016e. Present a mechatronic system having able to determine the concentration of carotenoids. Am. J. Eng. Applied Sci., 9: 1106-1111. DOI: 10.3844/ajeassp.2016.1106.1111

Aversa, R., R.V. Petrescu, R. Sorrentino, F.I.T. Petrescu and A. Apicella, 2016f. Hybrid ceramo-polymeric nanocomposite for biomimetic scaffolds design and preparation. Am. J. Eng. Applied Sci., 9: 1096-1105. DOI: 10.3844/ajeassp.2016.1096.1105

Aversa, R., V. Perrotta, R.V. Petrescu, C. Misiano and F.I.T. Petrescu et al., 2016g. From structural colors to super-hydrophobicity and achromatic transparent protective coatings: Ion plating plasma assisted $\mathrm{TiO}_{2}$ and $\mathrm{SiO}_{2}$ Nano-film deposition. Am. J. Eng. Applied Sci., 9: 1037-1045.

DOI: 10.3844/ajeassp.2016.1037.1045

Aversa, R., R.V. Petrescu, F.I.T. Petrescu and A. Apicella, 2016h. Biomimetic and evolutionary design driven innovation in sustainable products development. Am. J. Eng. Applied Sci., 9: 1027-1036. DOI: 10.3844/ajeassp.2016.1027.1036

Aversa, R., R.V. Petrescu, A. Apicella and F.I.T. Petrescu, 2016i. Mitochondria are naturally micro robots-a review. Am. J. Eng. Applied Sci., 9: 991-1002. DOI: 10.3844/ajeassp.2016.991.1002

Aversa, R., R.V. Petrescu, A. Apicella and F.I.T. Petrescu, 2016j. We are addicted to vitamins C and E-A review. Am. J. Eng. Applied Sci., 9: 1003-1018. DOI: 10.3844/ajeassp.2016.1003.1018

Aversa, R., R.V. Petrescu, A. Apicella and F.I.T. Petrescu, 2016k. Physiologic human fluids and swelling behavior of hydrophilic biocompatible hybrid ceramopolymeric materials. Am. J. Eng. Applied Sci., 9: 962-972. DOI: 10.3844/ajeassp.2016.962.972

Aversa, R., R.V. Petrescu, A. Apicella and F.I.T. Petrescu, 20161. One can slow down the aging through antioxidants. Am. J. Eng. Applied Sci., 9: 1112-1126. DOI: 10.3844/ajeassp.2016.1112.1126

Aversa, R., R.V. Petrescu, A. Apicella and F.I.T. Petrescu, $2016 \mathrm{~m}$. About homeopathy or «Similia similibus curentur 》. Am. J. Eng. Applied Sci., 9: 1164-1172. DOI: 10.3844/ajeassp.2016.1164.1172

Aversa, R., R.V. Petrescu, A. Apicella and F.I.T. Petrescu, 2016n. The basic elements of life's. Am. J. Eng. Applied Sci., 9: 1189-1197. DOI: 10.3844/ajeassp.2016.1189.1197

Aversa, R., F.I.T. Petrescu, R.V. Petrescu and A. Apicella, 2016o. Flexible stem trabecular prostheses. Am. J. Eng. Applied Sci., 9: 1213-1221. DOI: 10.3844/ajeassp.2016.1213.1221

Aversa, R., R.V.V. Petrescu, A. Apicella and F.I.T. Petrescu, 2017a. Nano-diamond hybrid materials for structural biomedical application. Am. J. Biochem. Biotechnol., 13: 34-41.

DOI: $10.3844 / a j b b s p .2017 .34 .41$ 
Aversa, R., R.V. Petrescu, B. Akash, R.B. Bucinell and J.M. Corchado et al., 2017b. Kinematics and forces to a new model forging manipulator. Am. J. Applied Sci., 14: 60-80.

DOI: 10.3844/ajassp.2017.60.80

Aversa, R., R.V. Petrescu, A. Apicella, I.T.F. Petrescu and J.K. Calautit et al., 2017c. Something about the $\mathrm{V}$ engines design. Am. J. Applied Sci., 14: 34-52. DOI: 10.3844/ajassp.2017.34.52

Aversa, R., D. Parcesepe, R.V.V. Petrescu, F. Berto and G. Chen et al., 2017d. Process ability of bulk metallic glasses. Am. J. Applied Sci., 14: 294-301. DOI: 10.3844/ajassp.2017.294.301

Aversa, R., R.V.V. Petrescu, B. Akash, R.B. Bucinell and J.M. Corchado et al., 2017e. Something about the balancing of thermal motors. Am. J. Eng. Applied Sci., 10: 200.217. DOI: 10.3844/ajeassp.2017.200.217

Berto, F., R.V.V. Petrescu and F.I.T. Petrescu, 2016a. A review of recent results on $3 \mathrm{D}$ effects. Am. J. Eng. Applied Sci., 9:1247-1260.

DOI: 10.3844/ajeassp.2016.1247.1260

Berto, F., R.V.V. Petrescu and F.I.T. Petrescu, $2016 \mathrm{~b}$. Three-dimensional in bonded joints: A short review. Am. J. Eng. Applied Sci., 9:1261-1268. DOI: 10.3844/ajeassp.2016.1261.1268

Berto, F., A. Gagani, R.V.V. Petrescu and F.I.T. Petrescu, 2016c. Key-hole notches in isostatic graphite: A review of some recent data. Am. J. Eng. Applied Sci., 9: 1292-1300. DOI: 10.3844/ajeassp.2016.1292.1300

Berto, F., A. Gagani, R. Aversa, R.V.V. Petrescu and A. Apicella et al., 2016d. Multiaxial fatigue strength to notched specimens made of 40CrMoV13.9. Am. J. Eng. Applied Sci., 9: 1269-1291. DOI: 10.3844/ajeassp.2016.1269.1291

Chou, F., A. Hawkes and E. Landau, 2017. NASA data used to discover eighth planet circling distant star. Jet Propulsion Laboratory, Pasadena, California Institute of Technology.

Kepler Mission website on www.nasa.gov. https://www.nasa.gov/mission_pages/kepler/main/ index.html

Mirsayar, M.M., V.A. Joneidi, R.V.V. Petrescu, F.I.T. Petrescu and F. Berto, 2017. Extended MTSN criterion for fracture analysis of soda lime glass. Eng. Fracture Mechanics, 178: 50-59. DOI: $10.1016 /$ j.engfracmech.2017.04.018

Petrescu, F.I.T., 2009. New aircraft. Proceedings of the 3rd International Conference on Computational Mechanics, Oct. 29-30, Brasov, Romania.

Petrescu, F.I.T., 2012a. Cold Nuclear Fusion. 1st Edn., Create Space, USA, ISBN-10: 1478234261, pp: 80.

Petrescu, F.I.T., 2012b. Particle annihilation - a source of renewable energy? Infinite Energy Magazine, LuLu Publishers, USA.
Petrescu, F.I.T., 2016 Valorificarea Traditiei Ingineresti Romanesti-I. 1st Edn., CreateSpace Independent Publishing Platform, USA, ISBN-10: 1536889946, pp: 152.

Petrescu, F.I.T. and J.K. Calautit, 2016a. About nano fusion and dynamic fusion. Am. J. Applied Sci., 13: 261-266. DOI: 10.3844/ajassp.2016.261.266

Petrescu, F.I. and J.K. Calautit, 2016b. About the light dimensions. Am. J. Applied Sci., 13:321-325. DOI: 10.3844 /ajassp.2016.321.325

Petrescu, F.I. and R.V. Petrescu, 2011a. Memories about Flight. 1st Edn., CreateSpace, pp: 652.

Petrescu, F.I. and R.V. Petrescu, 2011b. Mechanical Systems, Serial and Parallel. 1st Edn., lulu.com Publisher, London, UK. ISBN-10: 1446600394, pp: 124.

Petrescu, R.V. and F.I.T. Petrescu, 2012a. Northrop. 1st Edn., Books on Demand, ISBN-10: 3848209322, pp: 142.

Petrescu, F.I. and R.V. Petrescu, 2012b. New Aircraft II. 1 st Edn., Books on Demand, pp: 138.

Petrescu, F.I. and R.V. Petrescu, 2012c. MecatronicaSisteme Seriale Si Paralele. 1st Edn., Create Space Publisher, USA, ISBN-13: 978-1-4750-6613-5, pp: 128.

Petrescu, F.I. and R.V. Petrescu, 2012d. Kinematics of the planar quadrilateral mechanism. Engevista, 14: 345-348.

Petrescu, R.V. and F.I. Petrescu, 2013a. Lockheed Martin. 1st Edn., CreateSpace, pp: 114.

Petrescu, R.V. and F.I. Petrescu, 2013b. Northrop. 1st Edn., CreateSpace, pp: 96.

Petrescu, R.V. and F.I. Petrescu, 2013c. The Aviation History or New Aircraft I Color. 1st Edn., CreateSpace, pp: 292.

Petrescu, F.I. and R.V. Petrescu, 2013d. Cinematics of the 3R Dyad. Engevista, 15: 118-124.

Petrescu, F.I. and R.V. Petrescu, 2016a. Parallel moving mechanical systems kinematics. ENGE-VISTA, 18: 455-491.

Petrescu, F.I. and R.V. Petrescu, 2016b. Direct and inverse kinematics to the anthropomorphic robots. ENGEVISTA, 18: 109-124.

Petrescu, F.I. and R.V. Petrescu, 2016c. Dynamic cinematic to a structure 2R. Revista Geintec-Gestao Inovacao E Tecnologias, 6: 3143-3154.

Petrescu, R.V.V., R. Aversa, A. Apicella, F. Berto and S. Li et al., 2016a. Ecosphere protection through green energy. Am. J. Applied Sci., 13: 1027-1032. DOI: 10.3844/ajassp.2016.1027.1032

Petrescu, F.I.T., A. Apicella, R.V.V. Petrescu, S.P. Kozaitis and R.B. Bucinell et al., 2016b. Environmental protection through nuclear energy. Am. J. Applied Sci., 13: 941-946.

DOI: 10.3844/ajassp.2016.941.946 
Petrescu, R.V., R. Aversa, A. Apicella and F.I. Petrescu, 2016c. Future medicine services robotics. Am. J. Eng. Applied Sci., 9: 1062-1087. DOI: 10.3844/ajeassp.2016.1062.1087

Petrescu, R.V., R. Aversa, B. Akash, F. Berto and A. Apicella et al., 2017a. Forces of a 3R Robot. J. Mechatron. Robot., 1: 1-14. DOI: $10.3844 /$ jmrsp.2017.1.14

Petrescu, R.V., R. Aversa, B. Akash, F. Berto and A. Apicella et al., 2017b. Direct geometry and cinematic to the MP-3R systems. J. Mechatron. Robot., 1: 15-23. DOI: 10.3844/jmrsp.2017.15.23

Petrescu, R.V., R. Aversa, B. Akash, F. Berto and A. Apicella et al., 2017c. Dynamic elements at MP3R. J. Mechatron. Robot., 1: 24-37.

Petrescu, R.V., R. Aversa, B. Akash, F. Berto, A. Apicella and F.I.T. Petrescu, 2017d. Geometry and direct kinematics to MP3R with $4 \times 4$ operators. J. Mechatron. Robot., 1: 38-46.

Petrescu, R.V., R. Aversa, A. Apicella, M.M. Mirsayar and S. Kozaitis et al., 2017e. Current stage in the field of mechanisms with gears and rods. J. Mechatron. Robot., 1: 47-57.

Petrescu, R.V., R. Aversa, A. Apicella, M.M. Mirsayar and S. Kozaitis et al., 2017f. Geometry and inverse kinematic at the MP3R mobile systems. J. Mechatron. Robot., 1: 58-65.

Petrescu, R.V., R. Aversa, A. Apicella, M.M. Mirsayar and S. Kozaitis et al., 2017g. Synthesis of optimal trajectories with functions control at the level of the kinematic drive couplings. J. Mechatron. Robot., 1: 66-74.

Petrescu, R.V., R. Aversa, A. Apicella, M.M. Mirsayar and S. Kozaitis et al., 2017h. The inverse kinematics of the plane system 2-3 in a mechatronic MP2R system by a trigonometric method. J. Mechatron. Robot., 1: 75-87.
Petrescu, R.V., R. Aversa, A. Apicella, M.M. Mirsayar and S. Kozaitis et al., 2017i Serial, anthropomorphic, spatial, mechatronic systems can be studied more simply in a plan. J. Mechatron. Robot., 1: 88-97.

Petrescu, R.V., R. Aversa, A. Apicella, M.M. Mirsayar and S. Kozaitis et al., 2017j. Analysis and synthesis of mechanisms with bars and gears used in robots and manipulators. J. Mechatron. Robot., 1: 98-108.

Petrescu, R.V., R. Aversa, A. Apicella, M.M. Mirsayar and S. Kozaitis et al., 2017k. Speeds and accelerations in direct kinematics to the MP3R systems. J. Mechatron. Robot., 1: 109-117.

Petrescu, R.V., R. Aversa, A. Apicella, M.M. Mirsayar and S. Kozaitis et al., 20171. Geometry and determining the positions of a plan transporter manipulator. J. Mechatron. Robot., 1: 118-126.

Safta A., KEPLER DAY: The Great Conquest of the Universe has begun!

http://www.descopera.ro/stiinta/4019478-ziuakepler-marea-cucerire-a-universului-a-inceput

Andreea Zaporojanu, KEPLER DAY: Looking for new Earths. http://www.descopera.ro/stiinta/929023ziua-kepler-in-cautarea-noilor-pamanturi

\section{Source of Figures}

Fig. 1:

https://ro.wikipedia.org/wiki/Planet $\% \mathrm{C} 4 \% 83$ teluric $\% \mathrm{C}$ 4\%83\#/media/File:4_Terrestrial_Planets_Size_Comp_Tr ue Color.png

Fig. 2-5:

http://www.descopera.ro/stiinta/4019478-ziua-keplermarea-cucerire-a-universului-a-inceput 